OPEN ACCESS

Edited by:

Jian Ouyang,

Dalian University of Technology, China

Reviewed by:

Pengfei Liu,

RWTH Aachen University, Germany

Huaping Wang,

Lanzhou University, China

*Correspondence:

Meng Guo

gm@bjut.edu.cn

Specialty section:

This article was submitted to

Structural Materials,

a section of the journal

Frontiers in Materials

Received: 28 February 2020 Accepted: 27 April 2020 Published: 22 May 2020

Citation:

Yang S, Li P, Guo M, Liao S and Wu H (2020) Study on Dynamic Load

Monitoring of an Enhanced Stress Absorption Layer. Front. Mater. 7:148. doi: 10.3389/fmats.2020.00148

\section{Study on Dynamic Load Monitoring of an Enhanced Stress Absorption Layer}

\author{
Sanqiang Yang ${ }^{1,2}$, Pengfei $\mathrm{Li}^{1}$, Meng Guo ${ }^{3 *}$, Songyang Liao ${ }^{1}$ and Haonan $\mathrm{Wu}^{4}$ \\ ${ }^{1}$ Hebei Province Civil Engineering Monitoring and Evaluation Technology Innovation Center, College of Civil Engineering and \\ Architecture, Hebei University, Baoding, China, ${ }^{2}$ School of Highway, Chang'an University, Xi'an, China, ${ }^{3}$ The Key Laboratory \\ of Urban Security and Disaster Engineering of Ministry of Education, Beijing University of Technology, Beijing, China, ${ }^{4}$ Rood \\ and Bridge Branch, Hebei Construction Group Corporation Limited, Baoding, China
}

An effective stress absorption layer can reduce the reflection crack. It can help to extend the service life of road. In this research, an enhanced stress absorption layer of slow crack (ESALOSC) is proposed and compared with the ordinary SBS modified asphalt stress absorbing layer. The strain data of two stress absorption layers under different loads, speeds and temperatures are collected by embedding sensors in the road, and the dynamic response laws of the two stress absorption layers under different conditions are analyzed. The results show that the asphalt pavement is a viscoelastic body and the measured results are consistent with the theoretical solution of layered elasticity: both stress absorbing layers are subjected to pressure. According to the comparison between dynamic overload test and static overload test, the strain deviation between the two sections increases from $11.6 \%$ of static load to $25.2 \%$ of dynamic load $(40 \mathrm{~km} / \mathrm{h}$ ). It indicates that the reinforced effect of geogrid is more obvious under dynamic load. By establishing the relationship between vehicle speed and dynamic response, a vehicle speed and dynamic response model for the ESALOSC is proposed. Based on the test data measured at four temperatures, a model of the temperature and dynamic response in the ESALOSC is proposed. The accuracy and effectiveness of the two models are verified by comparing with other experimental results. The ESALOSC is of great significance for improving the crack resistance of road. The research results provide technical support and theoretical model for the development of long-life pavement in China.

\section{Keywords: stress absorbing layer, geogrid, dynamic response, vehicle load, vehicle speed}

\section{INTRODUCTION}

With the rapid development of Chinese economy, the demand for transportation is increasing, and the country's requirements for road service levels are increasing. At present, most of the domestic transportation roads use semi-rigid bases (Sha, 2008). Investigations show that no matter in the south or the north of China, there will be a lot of cracks after 2 years of opening to traffic. After studying these cracks, it was found that more than half of the cracks was reflective cracks caused by temperature shrinkage and dry shrinkage (Zeng et al., 2013). The development of these cracks not only affect driving safety, but also shorten the road life. This shows that the existing domestic stress absorption layer can no longer meet the daily use needs, and the problem of reflective cracks on 
asphalt roads is becoming increasingly serious (Geng et al., 2012). Under this background, domestic and foreign scholars have proposed different methods to delay the occurrence and expansion of reflective cracks (Tschegg et al., 2007; Doh et al., 2009; Schlosser et al., 2013; Zhang et al., 2018; Ouyang et al., 2020).

The stress absorption layer has always been a research hotspot of asphalt pavement. Scholars have mainly studied the crack resistance mechanism of the stress absorption layer, the application performance of the material and the testing methods utilized to evaluate reflective cracking (Yoon et al., 2017). Iowa State University's Ceylan successfully simulated the stress intensity factor of crack propagation with neural network (NN) method, and studied the crack propagation mechanism (Ceylan et al., 2011). Zhao and Baek analyzed the reflection crack propagation mechanism under dynamic load through ABAQUS and found that increasing the vehicle speed could delay the development of reflection cracks (Baek and Alqadi, 2008; Zhao and Ni, 2009). Huang Xiaoming of Southeast University applied discrete element software to establish a crack model for a composite pavement structure with a semi-rigid base. It was found that a normal load could generate a horizontal stress concentration at the crack tip. The stress decreased around the crack tip (Wang et al., 2016). Sun Yazhen of Shenyang Jianzhu University used finite element software to simulate reflective cracks and found that under different loads, reflective cracks would expand in different ways (Sun et al., 2012).

Geogrid and various asphalt materials are the research focus of stress absorbing layer materials (Keller, 2016; Zornberg, 2017). Xue Yongchao of Southeast University designed a stress absorbing layer composed of epoxy asphalt and glass fiber geogrid, and tested it by drawing test, shear test and fatigue test. The results showed that the optimal ratio of epoxy asphalt was $2.0 \mathrm{~L} / \mathrm{m}^{2}$ (Xue et al., 2016). Silva used four-point fatigue test and rutting test, and found that the high proportion of ultra-fine rubber granule asphalt mixture prepared by drying has better fatigue resistance and the crack growth rate was slower (Silva et al., 2018). Khodaii Ali recommended that the maximum service life could be provided by placing the geogrid one third from the bottom of the covering layer (Khodaii et al., 2009). Zamora found that the geogrid has good crack resistance. High modulus geogrid had better performance (Zamora et al., 2011). The focus of these studies is to evaluate the actual properties of materials, and there is a lack of research on the mechanism of the action of materials in the road.

Aiming at the practical problems of reflection cracks, many testing methods were introduced into the experiments. Saride et al. used digital image correlation technology (DIC) to record the crack growth failure pattern and corresponding tensile strain, but DIC was very sensitive to moisture and dust in the air, which could lead to large errors (Kumar and Saride, 2017; Saride and Kumar, 2017). Ling Jianming invented Joint Motion Simulation System (JMSS) using sensors, which considered the influence of both traffic and thermal load. The test results showed that the performance of geotextile was better than stress absorbing layers, and polypropylene modified linoleum (Ling et al., 2019). Wang Huaping embedded fiber sensors in the interior of the road
TABLE 1 | Pavement structure layer.

\begin{tabular}{llc}
\hline Location & The structure layer & Corresponding thickness (cm) \\
\hline 1 & AC-13 & 4 \\
2 & AC-16 & 6 \\
3 & AC-25 & 8 \\
4 & Stress absorbing layer & 1 \\
5 & $5 \%$ cement stabilized gravel & 18 \\
6 & $4 \%$ cement stabilized gravel & 18 \\
7 & Graded crushed stone & 18 \\
\hline
\end{tabular}

and collected a wealth of strain data. The corresponding strain transfer theory and temperature error correction formula were put forward, and it was suggested to use low modulus asphalt as protection layer (Wang et al., 2018, 2019). Therefore, it is a developing trend to explore the strain law of road interior by using sensors, and it has good effect.

According to the current research status of stress absorption layers and reflective cracks at home and abroad, it is found that the currently designed stress absorption layers cannot meet the development needs of China's long-life pavement (Fan, 2015), and hinder the modernization of transportation in China. At the same time, there is a lack of systematic research on the action mechanism and performance evaluation of geogrids. In order to better solve the above problems, this paper uses sensors to collect the strain information in the road. The objective of this paper is to propose an enhanced stress absorption layer of slowing crack (ESALOSC) and summarizes the strain laws of ESALOSC. This stress absorption layer is composed of geogrid and rubber modified asphalt. The road performance of ESALOSC is verified by comparing with the performance of the ordinary SBS modified asphalt stress absorbing layer (OSMASAL). In this paper, sensors are arranged on two types of stress absorption layers to collect strain information under different loads, speeds and temperatures. This paper establishes the corresponding mathematical model based on the experimental data, which provides strong support for the follow-up research. The accuracy and effectiveness of the two models are verified by comparing with other experimental results. The research results provide theoretical support and technical guidance for the design of long-life roads, and have important engineering value.

\section{ENGINEERING DESCRIPTION}

The project locates on Cangshan Road, Fuping County, Hebei Province. Fuping County is a mountainous region, with high temperatures and high humidity in summer, concentrated precipitation, cold and snow in winter. The minimum daily temperature is $-15^{\circ} \mathrm{C}$. The road is laid out from west to east. The roadbed is silty clay. The driveway is designed as a two-way fourlane road. The ESALOSC and the OSMASAL are, respectively laid on Cangshan east road. The section of $\mathrm{K} 1+200-\mathrm{k} 1+400$ is selected to lay ESALOSC, which is composed of geogrid and rubber modified asphalt, and this part is called "Section A." 
TABLE 2 | The gradation composition of asphalt mixture.

\begin{tabular}{|c|c|c|c|c|c|c|c|c|c|c|c|c|c|}
\hline & \multicolumn{13}{|c|}{ The percentage of mass through the following screen $(\%)$} \\
\hline & 31.5 & 26.5 & 19.0 & 16.0 & 13.2 & 9.5 & 4.75 & 2.36 & 1.18 & 0.6 & 0.3 & 0.15 & 0.075 \\
\hline$A C-13$ & & & & 100 & 95 & 77 & 53 & 37 & 27 & 19 & 14 & 10 & 6 \\
\hline AC-16 & & & 100 & 95 & 84 & 70 & 48 & 34 & 25 & 18 & 13 & 9 & 6 \\
\hline AC-25 & 100 & 95 & 85 & 74 & 67 & 55 & 38 & 30 & 23 & 16 & 11 & 9 & 5 \\
\hline
\end{tabular}
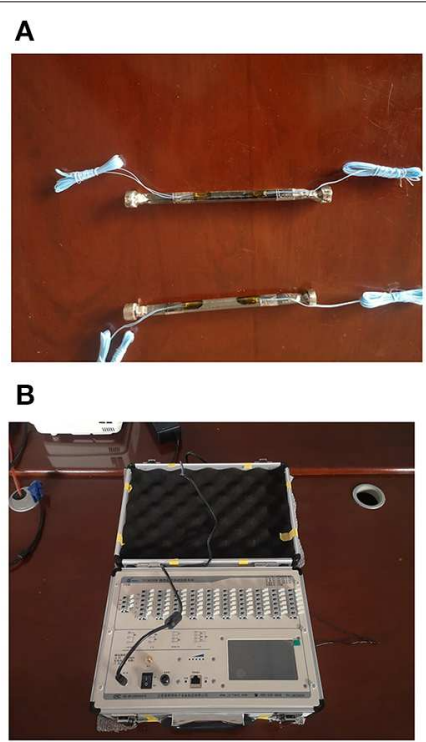

C

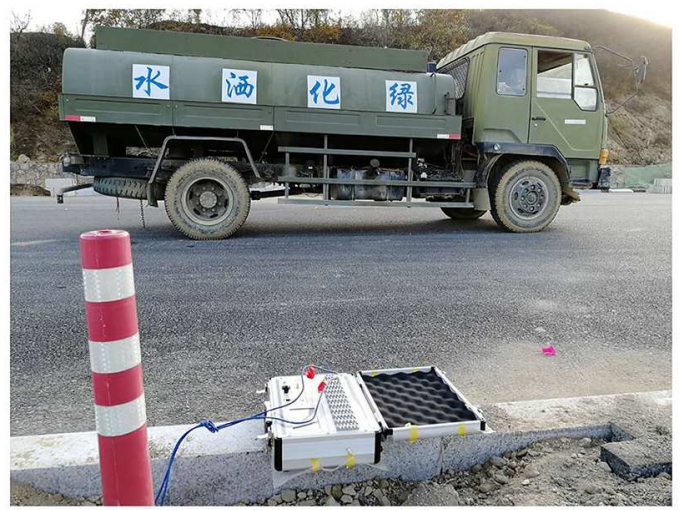

FIGURE 1 | (A) Two strain sensors, (B) strain collecting instrument, and (C) pictures of field tests.

The section of $\mathrm{K} 0+930-\mathrm{k} 1+070$ is selected to lay OSMASAL and compares with "Section A," which is hereinafter referred to "Section B." The pavement structure is shown in Table 1. The gradation composition of asphalt mixture is shown in Table 2. Figure 1 shows photos of the test system, where Figures 1A,B are photos of the sensors and strain gauge, respectively, and Figure $1 \mathrm{C}$ is a photo of the test process.

\section{DESIGN OF TEST SCHEME}

\section{Sensor Setup Scheme}

The sensor in this paper is a strain gauge, and the strain data is collected by placing the sensors on a stress absorption layer. The sensors are covered with fine aggregates and the same asphalt (Wang and Xiang, 2016). The sensors in section A are placed at 5 points and collectively referred to as "Group A." Similarly, the sensors in section B are also placed at 5 points and collectively referred to as "Group B." The sensors are located at the left-wheel track of the carriageway, and the survival rate of the sensors is $60 \%$. All conditions meet the requirements of the test. The details of the surviving sensors are shown in Table 3 . The location of the sensor is shown in Figures 2A,B.

\section{Test Plan}

In order to analyze the effects of load, speed, and temperature in the ESALOSC, the test is designed at different speeds, loads,
TABLE 3 | The location of the surviving sensors.

\begin{tabular}{lccc}
\hline $\begin{array}{l}\text { Measuring point } \\
\text { location }\end{array}$ & $\begin{array}{c}\text { Serial } \\
\text { number }\end{array}$ & $\begin{array}{c}\text { Measuring point } \\
\text { location }\end{array}$ & $\begin{array}{c}\text { Serial } \\
\text { number }\end{array}$ \\
\hline $\mathrm{K} 1+330$ & $\mathrm{~A} 2$ & $\mathrm{~K} 1+030$ & $\mathrm{~B} 2$ \\
$\mathrm{~K} 1+300$ & $\mathrm{~A} 3$ & $\mathrm{~K} 1+001$ & $\mathrm{~B} 3$ \\
$\mathrm{~K} 1+270$ & $\mathrm{~A} 4$ & $\mathrm{~K} 0+970$ & $\mathrm{~B} 4$ \\
\hline
\end{tabular}

and temperatures (Tan and Guo, 2013; Xiao et al., 2016). Plan 1 selects five speeds to study the effects of dynamic and static loads on ESALOSC. The three groups of tests conduct in sections A and B. The plans are shown in Table 4.

\section{DATA ANALYSIS}

The high-frequency strain gauge is used to collect the strain data of the two stress absorption layers. After installing the system, strain gauge starts to collect strain data. The above three plans are carried out three times, respectively. The maximum strain is extracted from the test data as the dynamic response of the pavement structure under each test condition. It is planned to ignore data with more than $10 \%$ deviation. The variation coefficient of all off the test data are below $4 \%$ in the same 

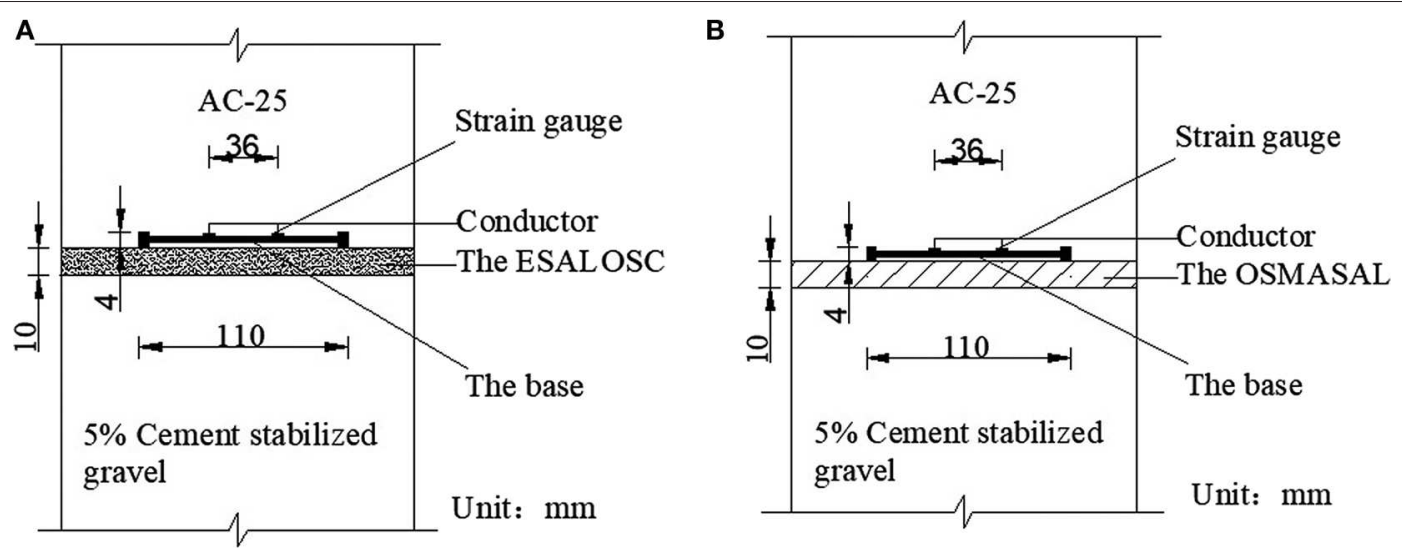

FIGURE 2 | (A) Sensor embedded position of the ESALOSC, and (B) sensor embedded position of the OSMASAL.

working condition. The tests are performed at different speed, load, temperature, and road structure conditions, so the size and distribution of the wheel load are different, which will cause the dynamic response of the pavement structure to be very different. According to the theory of layered elasticity, both stress-absorbing layers are affected by pressure, and the measured strains are both negative, which is consistent with the theoretical solution of layered elasticity (Yang et al., 2017).

\section{Effect of Load on ESALOSC}

Plan 1 prepares to study the impact of the load on the two stress absorption layers. The scheme is divided into a dynamic load part $(5-40 \mathrm{~km} / \mathrm{h})$ and a static load part $(0 \mathrm{~km} / \mathrm{h})$. The two dynamic load tests are shown in Figures 3A,B. Figure 3A is the image of the standard load vehicle (BZZ-100) passing at the A4 pile at a speed of $10 \mathrm{~km} / \mathrm{h}$, and Figure 3B is the image of the vehicle (13.9t) passing at the B4 pile position under the same speed. The results of plan 1 are shown in Figures 3C,D. The analysis of test data is shown in Table 5.

Figures $3 \mathbf{A}, \mathbf{B}$ shows that when the vehicle passes over the laying sensor, two obvious fluctuations occur on the strain image. The front strain is smaller than the rear strain, which indicates that the front strain is generated by the front wheel and the rear strain is generated by the rear wheel. At the same speed, the strain of both sections increases with the increase of the load. This phenomenon is caused by the increase of the load that causes the tire stiffness to increase, and the increased stiffness of the tire causes the dynamic response to increase on the road. The static load test shows that the load increasing from 10t to 13.9t, which causes the strain of section A and section B to increase by 29.2 and $40.8 \%$, respectively. The results show that the increase of static load has greater impact on section B than section A. In the dynamic load test at $5 \mathrm{~km} / \mathrm{h}$, the strain increases by 23.9 and $38.1 \%$ in section A and section B, respectively. The dynamic load tests at $10 \mathrm{~km} / \mathrm{h}$ shows that the strain increases by 20.3 and $38.2 \%$ in section $A$ and section $B$, respectively. In the $20 \mathrm{~km} / \mathrm{h}$ dynamic load test, the strain increases by 16.3 and $36.4 \%$ in section A and section B, respectively, and the $40 \mathrm{~km} / \mathrm{h}$ dynamic load test show that the strain increases by 10.5 and $35.7 \%$ in section $A$ and
TABLE 4 | Test plan

\begin{tabular}{lllc}
\hline $\begin{array}{l}\text { Test } \\
\text { plan }\end{array}$ & Vehicle speed(km/h) & Vehicle load $(\boldsymbol{t})$ & $\begin{array}{c}\text { The temperature of the } \\
\text { road surface }\left({ }^{\circ} \mathbf{C}\right)\end{array}$ \\
\hline 1 & (1); (2); (3)10; (4)20; (5)40 & (1)BZZ-100; (213.9 & 3 \\
2 & (1); (25; (3)10; (4)20; (5)40 & 13.9 & 3 \\
3 & 5 & BZZ-100 & (1)-8; (2)-3; (3); (4)3 \\
\hline
\end{tabular}

section $\mathrm{B}$, respectively. The above dynamic load tests show that the increase in dynamic load has greater impact on section $B$ than section A.

The data of five times show that the strain difference between the two pavements increases from 11.6 to $25.2 \%$ with the increase of the speed. It indicates that the reinforcement effect of the geogrid under dynamic load is more obvious than the static load, so it can be significantly improved the road carrying capacity. All the strains in the static load test come from the original load of the vehicle. The area of the stress-absorption layer that directly contact with the wheel is affected by pressure, and the area outside the wheel load edge is affected by tension. The geogrid can reduce the pressure and tension in the stress absorption layer, and reduce the corresponding strain. In the dynamic load test, the strain not only come from the vehicle's load, but also come from the vehicle's additional dynamic impact load. While dispersing the above pressure and tension, the geogrid also reduces the strain of the additional dynamic impact load.

\section{Effect of Velocity on ESALOSC}

The purpose of Plan 2 is to study the effect of vehicle speed on the stress absorption layer in section $\mathrm{A}$. The tests on piles A4 and B4 are shown in Figures 4A,B. Figures 4C,D are model images of dynamic response and speed. Table 6 shows the specific parameters of the two models in sections A and B, Table 7 lists the actual measured data of the $\mathrm{A} 2$ and $\mathrm{A} 3$ piles and the corresponding model data. The "deviation" in Table 7 refers to the deviation between the actual measured data at $\mathrm{A} 2$ or $\mathrm{A} 3$ pile and the data calculated by the model in this section. 

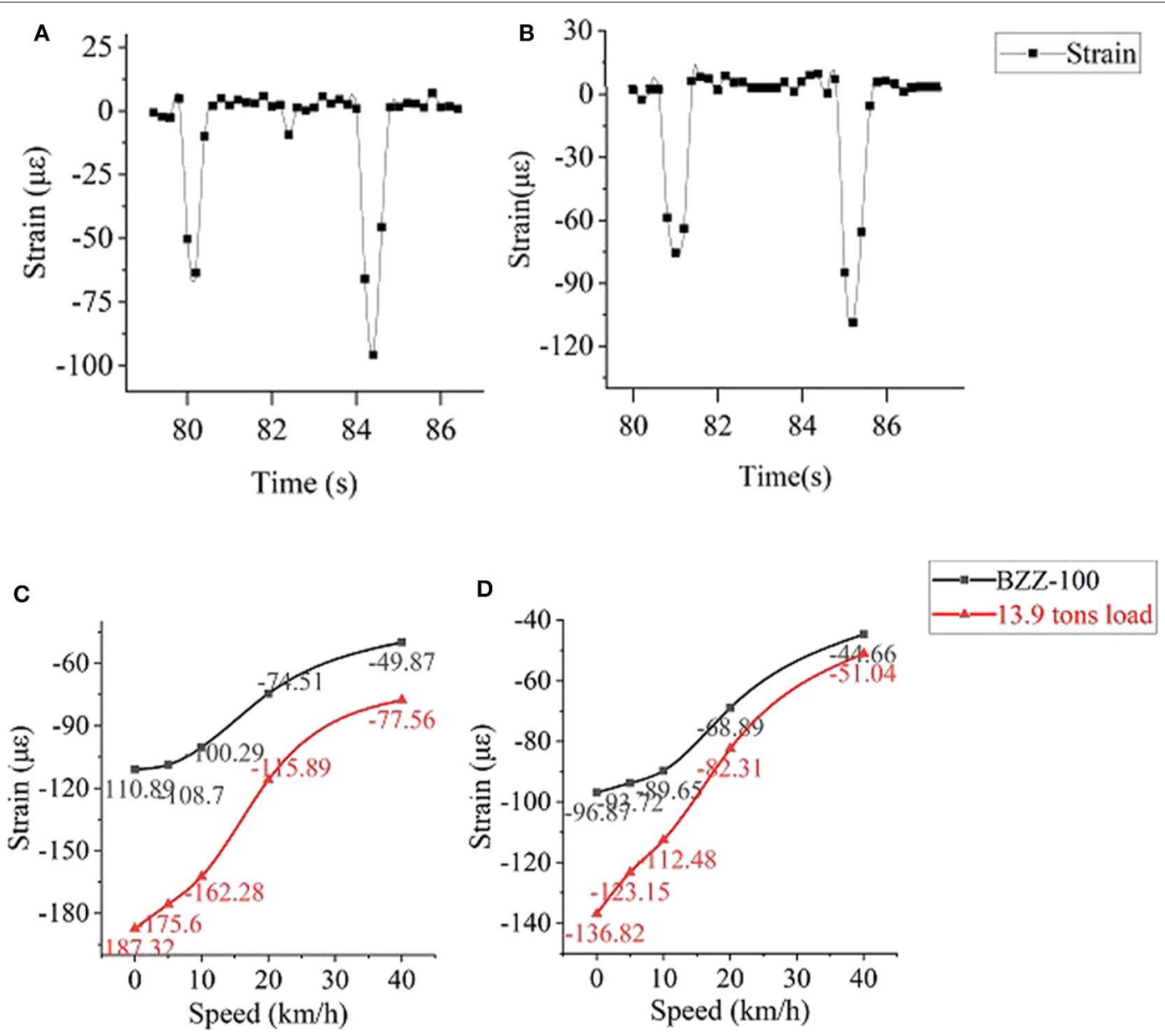

FIGURE 3 | (A) A4 pile's loading vehicle strain (10t, $10 \mathrm{~km} / \mathrm{h}), \mathbf{( B )}$ B4 pile's loading vehicle strain (13.9t, $10 \mathrm{~km} / \mathrm{h})$, (C) the results of plan 1 are shown in A4 pile, and (D) The results of plan 1 are shown in B4 pile.

TABLE 5 | Test 1 analysis.

\begin{tabular}{lccc}
\hline $\begin{array}{c}\text { Speed } \\
(\mathbf{k m} / \mathbf{h})\end{array}$ & $\begin{array}{c}\text { Strain difference ratio of } \\
\text { two loads in section } \\
\text { A (\%) }\end{array}$ & $\begin{array}{c}\text { Strain difference ratio of } \\
\text { two loads in section } \\
\text { B (\%) }\end{array}$ & $\begin{array}{c}\text { Two segment } \\
\text { difference (\%) }\end{array}$ \\
\hline 0 & 29.2 & 40.8 & 11.6 \\
5 & 23.9 & 38.1 & 14.2 \\
10 & 20.3 & 38.2 & 17.9 \\
20 & 16.3 & 36.4 & 23.5 \\
40 & 10.5 & 35.7 & 25.2 \\
\hline
\end{tabular}

Figures 4A,B show that as the speed increases, the dynamic response of the wheels in the two stress absorption layers gradually decreases. When the speed increases from stationary to $20 \mathrm{~km} / \mathrm{h}$, the strain decreases significantly. However, after the speed exceeds $20 \mathrm{~km} / \mathrm{h}$, the dynamic response gradually flattens. This phenomenon is caused by the increase in speed, which reduces the amount of time that the load acts on the sensor. This is shown in mechanics as: the increase in road strength and modulus affects the dynamic response of the road structure, which proves that the impact of low-speed vehicles on the road is greater than high-speed vehicles. Therefore, the model of speed and dynamic response is proposed in part A: $\varepsilon=36.63724 \ln v-$ 189.6703. Its correlation coefficient is above 0.97. At the same time, the measured data of the A2 and A3 piles are compared with the data obtained from the above model, and the deviation of data is within $\pm 4.68 \%$. The results show that the model can accurately reflect the strain caused by vehicles with different speeds in section $A$, and has high applicability. The slope " $A$ " of the $\varepsilon-v$ linear equation can represent the rate which the dynamic response change with the speed of the vehicle. Table 7 shows that comparing with the section $\mathrm{B}$, the strain in section $\mathrm{A}$ decreases less than section $B$ with the increase of the speed, which indicates that the speed has a smaller effect in section A.

\section{Effect of Temperature on ESALOSC}

In Plan 3, four measuring times are selected to represent different temperatures in a day (Guo et al., 2017; Ouyang et al., 2018; Guo and Tan, 2019). The measuring time are shown in Table 8. The tests at A2 and B2 piles are shown in Figures 5A,B. Figures 5C,D 

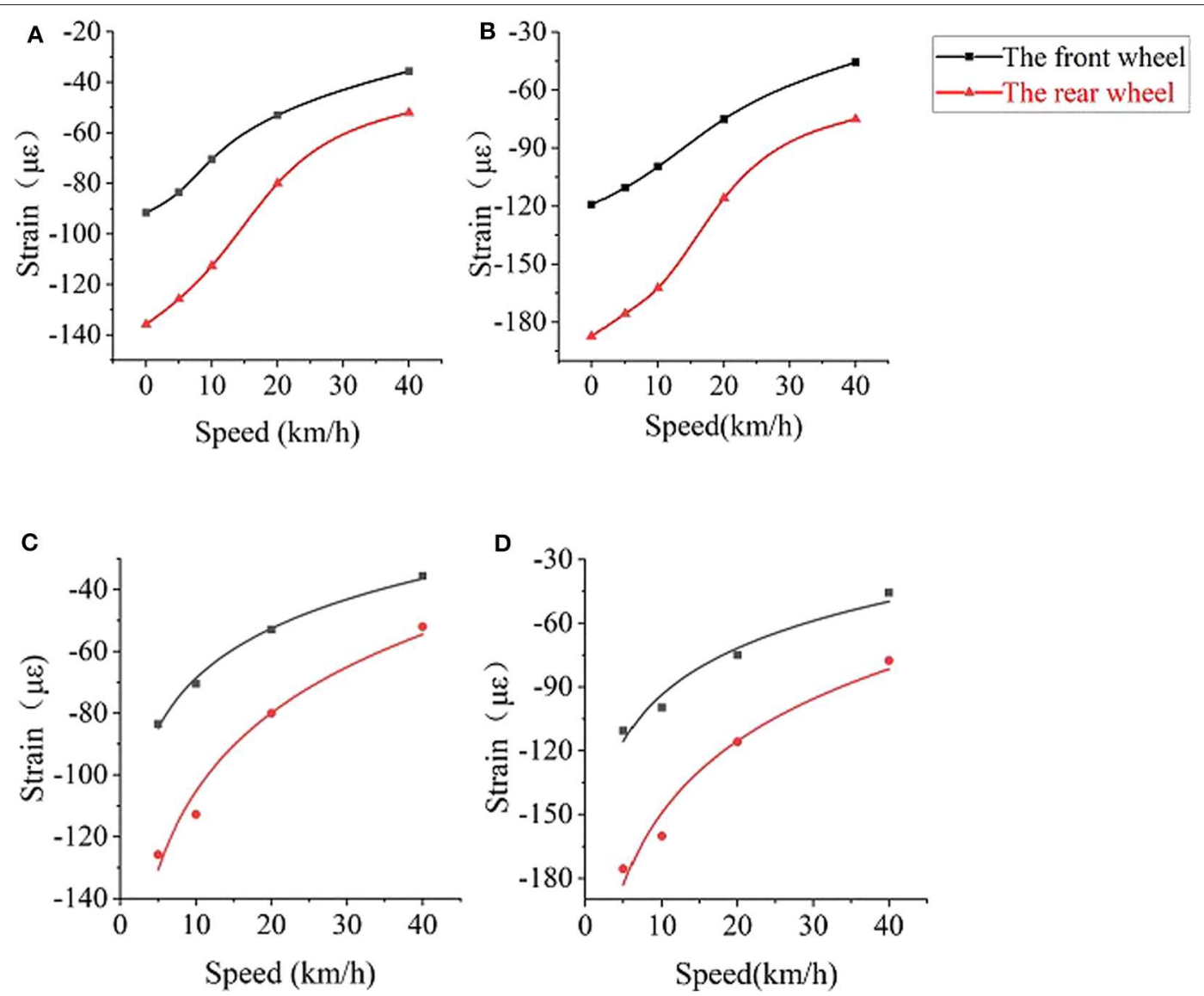

FIGURE 4 | (A) A4 pile's loading vehicle strain, (B) B4 pile's loading vehicle strain, (C) model of strain and speed in the section A, and (D) model of strain and speed in the section $B$.

TABLE 6 | Speed and strain model.

\begin{tabular}{|c|c|c|c|}
\hline \multirow{2}{*}{$\begin{array}{l}\text { Location } \\
\text { Section A }\end{array}$} & \multicolumn{2}{|c|}{ Regression coefficient } & \multirow{2}{*}{$\begin{array}{c}\text { Model } \\
\varepsilon=\begin{array}{c}36.63724 / n v- \\
189.6703\end{array}\end{array}$} \\
\hline & A & 36.63724 & \\
\hline & B & -189.6703 & \\
\hline & $\begin{array}{l}\text { The correlation } \\
\text { coefficient }\left(R^{2}\right)\end{array}$ & 0.97416 & \\
\hline \multirow[t]{3}{*}{ Section B } & A & 48.80782 & $\begin{aligned} \varepsilon= & 48.80782 \ln v- \\
& 261.58215\end{aligned}$ \\
\hline & $\mathrm{B}$ & -261.58215 & \\
\hline & $\begin{array}{l}\text { The correlation } \\
\text { coefficient }\left(R^{2}\right)\end{array}$ & 0.96792 & \\
\hline
\end{tabular}

are the model images of dynamic response and temperature. Table 9 shows the specific parameters of the two models in section A and B, Table 10 lists the actual measured data of the A3 and A4 piles and the corresponding model data. The "deviation" in Table 10 refers to the deviation between the data actual measured at A3 or A4 pile and the data calculated by the model in this section. The strain transfer efficiency mainly depends on the protective layer material. In this paper,
TABLE 7 | Verify the speed and strain model in section A.

\begin{tabular}{|c|c|c|c|c|c|}
\hline \multirow{2}{*}{$\begin{array}{l}\text { Speed } \\
(\mathrm{km} / \mathrm{h})\end{array}$} & \multicolumn{4}{|c|}{ Other pile actual measured data } & \multirow{2}{*}{$\begin{array}{c}\text { Data from the } \\
\text { model }(\mu \varepsilon)\end{array}$} \\
\hline & $\begin{array}{c}\text { A2 pile } \\
(\mu \varepsilon)\end{array}$ & $\begin{array}{c}\text { Deviation } \\
\text { (\%) }\end{array}$ & $\begin{array}{c}\text { A3 pile } \\
(\mu \varepsilon)\end{array}$ & $\begin{array}{c}\text { Deviation } \\
\text { (\%) }\end{array}$ & \\
\hline 5 & -127.42 & -2.51 & -125.75 & -3.37 & -130.705 \\
\hline 10 & -101.09 & -4.01 & -106.63 & 1.25 & -105.309 \\
\hline 20 & -81.51 & 1.99 & -79.95 & 0.04 & -79.915 \\
\hline 40 & -53.43 & -3.83 & -51.97 & -4.68 & -54.519 \\
\hline
\end{tabular}

TABLE 8 | Test time and road temperature.

\begin{tabular}{lccc}
$\begin{array}{l}\text { Measuring } \\
\text { time }\end{array}$ & $\begin{array}{c}\text { The temperature of the } \\
\text { road surface }\left({ }^{\circ} \mathbf{C}\right)\end{array}$ & $\begin{array}{c}\text { Measuring } \\
\text { time }\end{array}$ & $\begin{array}{c}\text { The temperature of the } \\
\text { road surface }\left({ }^{\circ} \mathbf{C}\right)\end{array}$ \\
\hline $12: 00$ & 3 & $0: 00$ & -3 \\
$18: 00$ & 0 & $6: 00$ & -8 \\
\hline
\end{tabular}

the two sections adopt the same protective layer material, so the two sections have the same strain transfer efficiency (Wang and Dai, 2019). 


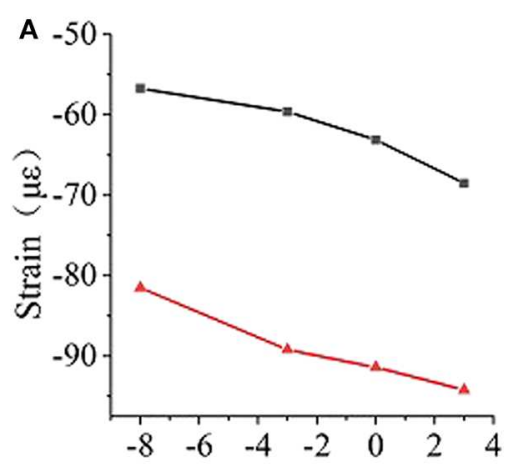

The temperature $\left({ }^{\circ} \mathrm{C}\right)$

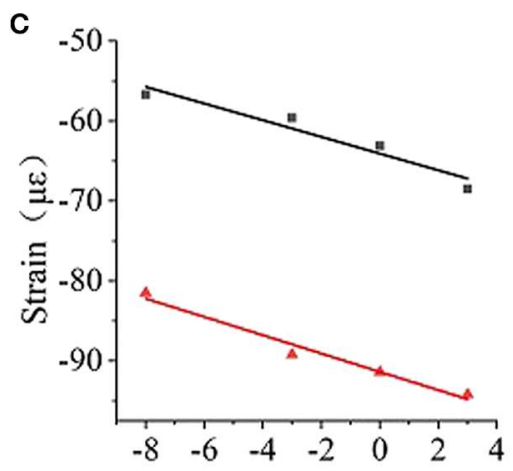

The temperature $\left({ }^{\circ} \mathrm{C}\right)$

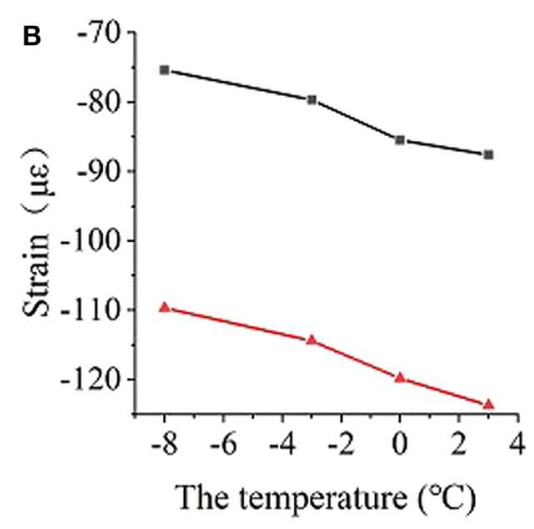

- - The front wheel
- - The rear wheel

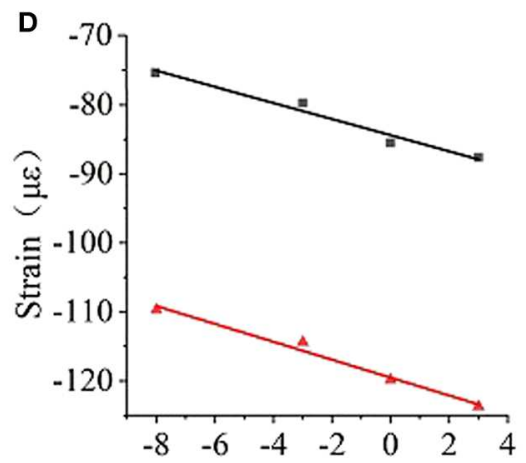

The temperature $\left({ }^{\circ} \mathrm{C}\right)$

FIGURE 5 | (A) A2 pile's loading vehicle strain, (B) B2 pile's loading vehicle strain, (C) model of strain and temperature in the section A, and (D) model of strain and temperature in the section $\mathrm{B}$.

TABLE 9 | Temperature and strain model.

\begin{tabular}{llcc}
\hline Location & \multicolumn{1}{c}{ Regression coefficient } & Model \\
\hline Section A & A & -1.14545 & $\varepsilon=-1.14545 t-$ \\
& & -91.36591 & 91.36591 \\
& B & 0.97226 & \\
& The correlation & & \\
Section B & coefficient $\left(R^{2}\right)$ & -1.29545 & $\varepsilon=-1.29545 t-$ \\
& A & -119.49091 & \\
& B & 0.98245 & \\
& The correlation & & \\
\hline & coefficient $\left(R^{2}\right)$ & &
\end{tabular}

Figures $\mathbf{5 A}, \mathbf{B}$ show that as the road temperature increases during the day, the dynamic response of vehicles also increases in the same area. Because asphalt is a temperature-sensitive material, its stiffness and modulus decrease with increasing temperature, which increases dynamic response. Since the temperature difference in the four tests is not large, the growth trend of the dynamic response is slow. Plan 3 verify the effect of temperature on the road. Therefore, the model of temperature
TABLE 10 | Verify the temperature and strain model of section A.

\begin{tabular}{lccccc}
\hline $\begin{array}{l}\text { Temperature } \\
\left({ }^{\circ} \mathbf{C}\right)\end{array}$ & \multicolumn{3}{c}{ Other pile actual measured data } & \multirow{2}{*}{$\begin{array}{c}\text { Data from the } \\
\text { model }(\mu \varepsilon)\end{array}$} \\
\cline { 2 - 5 } & $\begin{array}{c}\text { A3 pile } \\
(\mu \varepsilon)\end{array}$ & $\begin{array}{c}\text { Deviation } \\
(\%)\end{array}$ & $\begin{array}{c}\text { A4 pile } \\
(\mu \varepsilon)\end{array}$ & $\begin{array}{c}\text { Deviation } \\
(\%)\end{array}$ & \\
\hline 3 & -92.61 & -2.32 & -98.33 & 3.71 & -94.81 \\
0 & -90.05 & -1.45 & -88.92 & -2.68 & -91.37 \\
-3 & -90.85 & 3.32 & -85.77 & -2.46 & -87.93 \\
-8 & -85.17 & 3.60 & -83.59 & 1.68 & -82.21 \\
\hline
\end{tabular}

and dynamic response is proposed in part A: $\varepsilon=-1.14545 t-$ 91.36591. Its correlation coefficient is above 0.97. In addition, the measured data of the A3 and A4 piles are compared with the data obtained from the above model, and the deviation of data is within $\pm 3.71 \%$. The results show that the model can accurately reflect the strain caused by BZZ-100 vehicles at different temperatures and has high applicability. The slope " $A$ " of the $\varepsilon-t$ linear equation can represent the rate which the dynamic response changes with temperatures. As shown in Table 10: Comparing with the section $B$, the strain in the section A increases more slowly with temperature, which means that the temperature has less influence on the section A. 


\section{CONCLUSIONS}

Laying sensors on the two stress absorption layers, the strain data are collected under different speed, load, and temperature conditions. After collating the above data and analyzing the dynamic response of load, velocity and temperature in the two stress absorption layers, the following study can be concluded:

(1) According to the overload test data analysis: under static load conditions, the ESALOSC strain is $11.6 \%$ lower than the OSMASAL when overloaded 39\% (13.9t) on the BZZ-100 basis. In the dynamic load test under the same conditions, as the speed increasing, the strain difference between the two stress absorbing layers increase from 11.6 to $25.2 \%$. The results show that the reinforced effect of geogrid is more obvious under dynamic load, which can significantly improve the carrying capacity of asphalt road.

(2) By establishing the relationship between speed and dynamic response, the model of speed and dynamic response is proposed in the ESALOSC: $\varepsilon=36.63724 \ln v-189.6703$. The slope represents the rate which the strain change with the speed of vehicle. According to the regression results of the ESALOSC and the OSMASAL, the strains of the two stress-absorbing layers decrease with increasing speed. However, As the vehicle speed increases, the strain reduction rate on ESALOSC is smaller than on OSMASAL. It means that speed has less effect on the ESALOSC than the OSMASAL.

(3) According to the test data measured at four times: the temperature and dynamic response model is proposed in the ESALOSC: $\varepsilon=-1.14545 t-91.36591$. The slope represents

\section{REFERENCES}

Baek, J., and Alqadi, I. L. (2008). Finite element modeling of reflective cracking under moving vehicular loading: investigation of the mechanism of reflective cracking in hot-mix asphalt overlays reinforced with interlayer systems. Airfield Highway Pavements 329, 74-85. doi: 10.1061/410 05(329)7

Ceylan, H., Gopalakrishnan, K., and Lytton, R. L. (2011). Neural networks modeling of stress growth in asphalt overlays due to load and thermal effects during reflection cracking. J. Mater. Civil Eng. 23, 221-229. doi: 10.1061/(ASCE)MT.1943-5533.0000153

Doh, Y. S., Baek, S. H., and Kim, K. W. (2009). Estimation of relative performance of reinforced overlaid asphalt concretes against reflection cracking due to bending more fracture. Constr. Build. Mater. 23, 1803-1807. doi: 10.1016/j.conbuildmat.2008.09.027

Fan, Y. H. (2015). Study on the interlayer treatment methods of old cement concrete pavement and asphalt overlay. Highway Eng. 40, 27-31. doi: 10.3969/j.issn.1674-0610.2015.05.007

Geng, L. T., Ren, R. B., Guo, Y. Q., and Chang, Y. G. (2012). Experimental research on asphalt mixture for stress absorbing membrane interlayer. J. Build. Mater. 15, 570-574. doi: 10.3969/j.issn.1007-9629.2012.04.027

Guo, M., and Tan, Y. Q. (2019). Interaction between asphalt and mineral fillers and its correlation to mastics' viscoelasticity. Int. J. Pavement. Eng. 1-10. doi: 10.1080/10298436.2019.1575379. [Epub ahead of print].

Guo, M., Tan, Y. Q., Hou, Y., Wang, L. B., and Wang, Y. Q. (2017). Improvement of evaluation indicator of interfacial interaction between asphalt binder and mineral fillers. Constr. Build. Mater. 151, 236-245. doi: 10.1016/j.conbuildmat.2017.05.003

Keller, G. R. (2016). Application of geosynthetics on low-volume roads. Transp. Geotech. 8, 119-131. doi: 10.1016/j.trgeo.2016.04.002 the rate which the dynamic response change with temperature. According to the regression results of the two sections, the strain of both the two stress-absorbing layers increases with the increasing of temperature. In the two sections, the ESALOSC strain increases at a lower rate with the increase of temperature. It means that temperature has less effect on the ESALOSC than the OSMASAL.

\section{DATA AVAILABILITY STATEMENT}

The raw data supporting the conclusions of this article will be made available by the authors, without undue reservation, to any qualified researcher.

\section{AUTHOR CONTRIBUTIONS}

PL and SL conducted the experiments. SY is the supervisor of this research work. MG and PL helped writing. SY, PL, MG, SL, and HW performed the characterization and data analysis. All authors involved the analysis of experimental data and manuscript preparation.

\section{FUNDING}

This research was supported by Hebei Provincial Natural Science Foundation Funded Project (E2018201106), Hebei Provincial Department of Construction Science and Technology Project (130000021); Baoding Science and Technology Bureau Science and Technology Project (1911ZG003).

Khodaii, A., Fallah, S., and Moghadas, N. F. (2009). Effects of geosynthetics on reduction of reflection cracking in asphalt overlays. Geotext. Geomembranes 27, 1-8. doi: 10.1016/j.geotexmem.2008.05.007

Kumar, V. V., and Saride, S. (2017). Use of digital image correlation for the evaluation of flexural fatigue behavior of asphalt beams with geosynthetic interlayers. Transp. Res. Rec. 2631, 55-64. doi: 10.3141/2631-06

Ling, J. M., Wei, F. L., Gao, J. H., Zhang, J. K., Tian, Y., and Li, Y. T. (2019). New test method for measuring reflective cracking in hot-mix asphalt overlay pavements. Transp. Res. Rec. 2673, 327-336. doi: 10.1177/036119811 9841040

Ouyang, J., Yang, W. T., Chen, J. J., and Han, B. G. (2020). Effect of superplasticizer and wetting agent on pavement properties of cold recycled mixture with bitumen emulsion and cement. J. Mater. Civil Eng. 32:04020136. doi: 10.1061/(ASCE)MT.1943-5533.0003194

Ouyang, J., Zhao, J. Y., and Tan, Y. Q. (2018). Modeling mechanical properties of cement asphalt emulsion mortar with different asphalt to cement ratios and temperatures. J. Mater. Civil Eng. 30:04018263. doi: 10.1061/(ASCE)MT.1943-5533.0002480

Saride, S., and Kumar, V. V. (2017). Influence of geosynthetic-interlayers on the performance of asphalt overlays on pre-cracked pavements. Geotext. Geomembranes 45, 184-196. doi: 10.1016/j.geotexmem.2017.01.010

Schlosser, F., Mikolaj, J., Zatkalikova, V., Sramek, J., Durekova, D., and Remek, L. (2013). Deformation properties and fatigue of bituminous mixtures. Adv. Mater. Sci. Eng. 2013, 1-7. doi: 10.1155/2013/701764

Sha, A. M. (2008). Material characteristics of semi-rigid base. China J. Highway 21, 1-5. doi: 10.19721/j.cnki.1001-7372.2008.01.001

Silva, L. D., Benta, A., and Picado, S. L. (2018). Asphalt rubber concrete fabricated by the dry process: Laboratory assessment of resistance against reflection cracking. Constr. Build. Mater. 160, 539-550. doi: 10.1016/j.conbuildmat.2017.11.081 
Sun, Y. Z., Zhai, Y. X., and Li, N. (2012). Analysis on the mechanism of reflection crack propagation and anti-crack effect of asphalt pavement. J. Shenyang Jianzhu Univ. 28, 1023-1029.

Tan, Y. Q., and Guo, M. (2013). Using surface free energy method to study the cohesion and adhesion of asphalt mastic. Constr. Build. Mater. 47, 254-260. doi: 10.1016/j.conbuildmat.2013.05.067

Tschegg, E. K., Macht, J., Jamek, M., and Steigenberger, J. (2007). Mechanical and fracture-mechanical properties of asphalt-concrete interfaces. ACI Mater. J. 104, 474-480. doi: 10.14359/18903

Wang, H. P., and Dai, J. G. (2019). Strain transfer analysis of fiber bragg grating sensor assembled composite structures subjected to thermal loading. Compos. Part B Eng. 162, 303-313. doi: 10.1016/j.compositesb.2018.11.013

Wang, H. P., Jiang, L. Z., and Xiang, P. (2018). Improving the durability of the optical fiber sensor based on strain transfer analysis. Opt. Fiber Technol. 42, 97-104. doi: 10.1016/j.yofte.2018.02.004

Wang, H. P., and Xiang, P. (2016). Strain transfer analysis of optical fiber based sensors embedded in an asphalt pavement structure. IEEE Proc. Sci. Meas. Tech. 27:075106. doi: 10.1088/0957-0233/27/7/075106

Wang, H. P., Xiang, P., and Jiang, L. Z. (2019). Strain transfer theory of industrialized optical fiber-based sensors in civil engineering: a review on measurement accuracy, design and calibration. Sensor Actuat. A Phys. 285, 414-426. doi: 10.1016/j.sna.2018.11.019

Wang, X. L., Huang, X. M., and Dian, J. G. (2016). Analysis on the mechanism of LSPM in preventing reflection crack of semi-rigid asphalt pavement. J. Transp. Res. Develop. 33, 12-18. doi: 10.3969/j.issn.1002-0268.2016.07.003

Xiao, C., Qiu, Y. J., Ai, C. F., and Huang, B. (2016). Experiment on dynamical characteristics of asphalt pavement under vehicle load. J. Changan Univ. 36, 26-34. doi: 10.19721/j.cnki.1671-8879.2016.02.004

Xue, Y. C., Qian, Z. D., and Jia, W. (2016). Design and evaluation of epoxy asphalt geogrid stress-absorbing laye. J. Southeast Univ. 32, 93-98. doi: 10.3969/j.issn.1003-7985.2016.01.016

Yang, Y., Liu, Z., Xin, Y. B., Liu, H. F., and Qu, X. (2017). Evolution law of strain response of semi-rigid asphalt pavement under dynamic loading. J. China Foreign Highway 37, 51-55. doi: 10.14048/j.issn.1671-2579.2017.02.011
Yoon, Y., Patel, S., Ji, R., and Hastak, M. (2017). Current state of reflective cracking in the United States. J. Constr. Eng. Manage. ASCE 143:04016099. doi: 10.1061/(ASCE)CO.1943-7862.0001246

Zamora, B. D., Calzada, P. M. A., Castro, F. D., and Vega, Z. A. (2011). Evaluation of anti-reflective cracking systems using geosynthetics in the interlayer zone. Geotext. Geomembranes 29, 130-136. doi: 10.1016/j.geotexmem.2010.10.005

Zeng, M. L., Luo, D., Wu, C. F., and Wu, Z. X. (2013). Anti-cracking properties of cement stabilized crushed stone pavement base materials of different aggregate structures. J. Hunan Univ. 40, 1-7. doi: 10.3969/j.issn.1674-2974.2013. 10.001

Zhang, K., Zhang, Z. Q., and Luo, Y. F. (2018). Material composition design and anticracking performance evaluation of asphalt rubber stressabsorbing membrane interlayer (AR-SAMI). Adv. Mater. Sci. Eng. 2018, 1-11. doi: 10.1155/2018/8560604

Zhao, Y. J., and Ni, F. J. (2009). Reflective cracking viscoelastic response of asphalt concrete under dynamic vehicle loading. J. Southeast Univ. 25, 391-394.

Zornberg, J. G. (2017). Functions and applications of geosynthetics in roadways. Procedia Eng. 189, 298-306. doi: 10.1016/j.proeng.2017.05.048

Conflict of Interest: HW was employed by the company Hebei Construction Group Corporation Limited.

The remaining authors declare that the research was conducted in the absence of any commercial or financial relationships that could be construed as a potential conflict of interest.

Copyright $\odot 2020$ Yang, Li, Guo, Liao and Wu. This is an open-access article distributed under the terms of the Creative Commons Attribution License (CC BY). The use, distribution or reproduction in other forums is permitted, provided the original author(s) and the copyright owner(s) are credited and that the original publication in this journal is cited, in accordance with accepted academic practice. No use, distribution or reproduction is permitted which does not comply with these terms. 